\title{
Heat Affecting Zone Analysis of Polycarbonate in Laser Beam Machining Using Response Surface Methodology
}

\begin{tabular}{|c|c|c|c|}
\hline $\begin{array}{c}\text { Girish Dutt Gautam } \\
\text { Department of Mechanical } \\
\text { Engineering Jaypee University } \\
\text { of Engineering \& Technology, } \\
\text { Guna -MP (India) } \\
\text { Girish.gautam1985@gmail.com }\end{array}$ & $\begin{array}{c}\text { Shailendra Kumar } \\
\text { Department of Mechanical } \\
\text { Engineering Jaypee } \\
\text { University of Engineering } \\
\& \text { Technology, Guna -MP } \\
\text { (India) }\end{array}$ & $\begin{array}{c}\text { Ishan Khan } \\
\text { Department of Mechanical } \\
\text { Engineering Jaypee } \\
\text { University of Engineering } \\
\text { \& Technology, Guna -MP } \\
\text { (India) }\end{array}$ & $\begin{array}{c}\text { Gavendra Norkey } \\
\text { Department of Mechanical } \\
\text { Engineering Jaypee } \\
\text { University of Engineering } \\
\& \text { Technology, Guna -MP } \\
\text { (India) }\end{array}$ \\
\hline
\end{tabular}

\begin{abstract}
Laser beam machining (LBM) is today the most common industrial application of Laser for almost whole range of engineering materials. The change in metallurgical characteristics of laser machined work parts is mainly governed by Heat Affected Zone (HAZ). Therefore, it is required to minimize the HAZ during laser machining by controlling various factors.

In this research paper, the effect of process parameters such as laser power, cutting speed and gas pressure on HAZ for Polycarbonate (PC) material in laser cutting are discussed. L-27 orthogonal array was selected for full factorial design to better understanding of interaction between process parameters. Model equations of HAZ have been selected from literature survey and the values of heat affected zone (HAZ) for
\end{abstract}

Polycarbonate was calculated using these model equations. These model equations provide most affecting parameters, interaction affect of parameters and provide optimized input parameters at optimum HAZ. Entire analysis and optimization process has been done with Minitab® 14 software using Response Surface Methodology (RSM).

Keywords: Laser Beam Machining, Polycarbonate, Heat Affected Zone, Response Surface Methodology

\section{INTRODUCTION}

LASER (Light Amplification for Stimulated Emission of Radiation) is a mechanism for emitting electromagnetic radiation, often visible light, via the process of stimulated emission. Laser is a powerful source of light having extraordinary properties which are not found in the normal light sources are coherent, monochromatic and higher degree of directionality $[1,2]$.

Laser beam machining is a thermal energy based advanced machining process in which the material is removed by melting, vaporization and chemical degradation of work material. When a high energy density laser beam is focused on work surface the thermal energy is absorbed which heats and transforms the work volume into a molten, vaporized or chemically changed state that can easily be removed by flow of high pressure assist gas jet [3]. LBM has wide range of applications in industries for cutting operation, drilling operation, welding, marking, sintering, heat treating etc. Machining like micromachining, micro drilling are used in aerospace industry, automobile industry, nuclear sector and civil structures and electronics industry. It serves low cost, fast processing, net shaping, precision and accuracy of operation with local machining [4].

Many types of lasers used in industries like gas laser (He-Ne, $\mathrm{CO}_{2}, \mathrm{Ar}, \mathrm{Kr}, \mathrm{N}_{2}$ etc.), chemical laser (hydrogen fluoride, deuterium fluoride), liquid (die) laser, metal vapor laser (He-Cd, He-Hg, He-Ag, Ne-Cu), solid state laser (Ruby laser, Nd: YAG, Nd: Glass, Nd: YLF etc.) and semiconductor laser.[5]

$\mathrm{Nd}$ : YAG and $\mathrm{CO}_{2}$ are most widely used for LBM application. From the early days of the high power lasers, Nd: YAG lasers were only available in pulsed mode, while $\mathrm{CO}_{2}$ lasers were available both in pulsed and continuous $(\mathrm{CW})$ mode. $\mathrm{CO}_{2}$ lasers have wavelength of $10 \mathrm{~mm}$ in infrared region. It has high average beam power, better efficiency and good beam quality. It is suitable for fine cutting of sheet metal at high speed. Nd: YAG lasers have low beam power but when operating in pulsed mode high peak powers enable it to machine even thicker materials. Also, shorter pulse duration suits for machining of thinner materials. Due to shorter wavelength $(1 \mathrm{~mm})$ it can be absorbed by high reflective materials which are difficult to machine by $\mathrm{CO}_{2}$ lasers. Choudhury et al. (2010) have conducted 
ELK

Asia Pacific Journals

an experiment to analyze the effect of laser power, cutting speed and compressed air pressure on three different thermoplastic materials i.e. polypropylene (PP), Polycarbonate (PC) and Polymethylmethacrylate (PMMA). Output variables they have selected HAZ, surface roughness and dimensional accuracy. They observed that laser power is the most affecting parameter which affects HAZ [6].

In this research paper, the effect of process parameters such as laser power, cutting speed and gas pressure on HAZ for Polycarbonate (PC) material in laser cutting are discussed based on model equations.

\section{DESIGN OF EXPERIMENTS}

Design of experiments technique is a very powerful tool which permits us to carry out the modeling and analysis of the influence of process variable on the response variables [7]. The response variable is an unknown function of the process Variables, which are known as design factors. The following features are of great importance in DOE:

- Striving to minimize the total number of trials

- Simultaneous all the variables determining the process according to special rules called algorithms.

- The use of a mathematical apparatus formulizing many actions of the experimenter.

- The selection of a clear-cut strategy permitting the experiments to make substantiated decisions after each series of trials or experiments.
ELK Asia Pacific Journals - Special Issue

ISBN: 978-81-930411-8-5

Response surface methodology (RSM) is a collection of mathematical and statistical techniques that are useful for modeling and analysis of problems in which output or response influenced by several variables and the goal is to find the correlation between the response and the variables and the goal is to find the correlation between the response and the variables. It can be used for optimizing the response. It is an the empirical modeling technique devoted to the evaluation of relations existing between a group of controlled experimental factors and the observed results of one or more selected criteria. A prior knowledge of the studied process is thus necessary to achieve a realistic model. [7]

The first step of RSM is to define the limits of the experimental domain to be explored. These limits are made as wide as possible to obtain a clear response from the model. The laser power, cutting speed and gas pressure are the process parameters, selected for the investigation. In the next step, the planning to accomplish the experiments by means of response surface methodology (RSM) using Box-Behnken Design with three variables, in total 15 runs, which are extracted from the standard design matrix. The main physical properties of PC are listed in table no. 1. A derived model equation is used for calculating the HAZ of PC by opting different parameters such as laser power, cutting speed, gas pressure. Levels of process parameters for Polycarbonate are listed in table 2.

Table 1 Physical properties of PC

\begin{tabular}{|c|c|c|c|c|c|}
\hline Polymer & $\begin{array}{c}\text { Yield Strength } \\
(\mathbf{M P a})\end{array}$ & $\begin{array}{c}\text { Ultimate Strength } \\
(\mathbf{M P a})\end{array}$ & $\begin{array}{c}\text { Density } \\
(\mathbf{g} / \mathbf{c m 3})\end{array}$ & $\begin{array}{c}\text { Temperature } \\
\left({ }^{\mathbf{0}} \mathbf{C}\right)\end{array}$ & $\begin{array}{c}\text { Service Temperature } \\
\mathbf{M i n} / \mathbf{m a x}\left({ }^{\mathbf{0}} \mathbf{C}\right)\end{array}$ \\
\hline PC & 62.2 & $62.8-72.4$ & 1.2 & 270 & $-40 \pm 120$ \\
\hline
\end{tabular}

Table 2 Levels of process parameters for PC

\begin{tabular}{|l|c|c|c|c|c|}
\hline \multicolumn{1}{|c|}{ Variable } & Symbol & Unit & Level 1 & Level 2 & Level 3 \\
\hline Laser power & $P$ & Watt & 100 & 150 & 200 \\
\hline Cutting speed & $V$ & $\mathrm{~m} / \mathrm{min}$ & 0.2 & 0.4 & 0.6 \\
\hline Gas pressure & $P$ & Bar & 2.0 & 3.0 & 4.0 \\
\hline
\end{tabular}


ELK

Asia Pacific Journals

Analysis of variance (ANOVA), for checking the adequacy of the model, is then performed in the subsequent step. The F ratio is calculated for $95 \%$ level of confidence. The value which are less than 0.05 are considered significant and the values greater than 0.05 are not significant and the model are adequate to represent the relationship between machining response and the machining parameters.

\section{RESULTS AND DISCUSSION}

The model equation for Polycarbonate (PC) has been taken from research paper "Laser cutting of polymeric materials: An experimental investigation" submitted by Choudhury, I. A. and Shirley, S. in 2010 [9]. With the help of these process parameters and selected model equation calculation of HAZ for polycarbonate (PC) will be done for L-27 orthogonal
ELK Asia Pacific Journals - Special Issue ISBN: 978-81-930411-8-5

array for full factorial design and regression analysis and optimization performed.

After calculating the values of the HAZ for PC, four important graphs can be plotted to analyze the effect of parameter on output parameter (HAZ) shown in figure 1 and figure 4 respectively. For HAZ after using full factorial design, data is analyzed by response surface methodology's Box- Behnken technique, which suggested an array of 15 experiments in randomized run order, especially for 3 designs, in coded variable done on MINITAB 14 software. Regression Analysis and ANOVA table for $\mathrm{HAZ}_{\mathrm{PC}}$ shown in table 4 and table 5 respectively.

$$
\text { HAZ }_{\mathrm{PC}}=16.996\left(P^{0.485} v^{-0.233} p^{-0.199}\right)
$$

Where, $P$ is laser power $(\mathrm{W}), v$ is cutting speed $(\mathrm{m} / \mathrm{min})$ and $p$ is gas pressure (bar)

Table 3 Calculated values of $\mathrm{HAZ}_{\mathrm{PC}}$

\begin{tabular}{|c|c|c|c|c|}
\hline $\begin{array}{c}\text { Exp. } \\
\text { No. }\end{array}$ & $\begin{array}{c}\text { Laser Power } \\
(\mathbf{W})\end{array}$ & $\begin{array}{c}\text { Cutting Speed } \\
(\mathbf{m} / \mathbf{m i n})\end{array}$ & $\begin{array}{c}\text { Air Pressure } \\
(\mathbf{b a r})\end{array}$ & $\begin{array}{c}\mathbf{H A Z}_{\mathbf{P C}} \\
(\boldsymbol{\mu m})\end{array}$ \\
\hline $\mathbf{1}$ & 100 & 0.2 & 2.0 & 201.04 \\
\hline $\mathbf{2}$ & 100 & 0.2 & 3.0 & 185.46 \\
\hline $\mathbf{3}$ & 100 & 0.2 & 4.0 & 175.14 \\
\hline $\mathbf{4}$ & 100 & 0.4 & 2.0 & 171.06 \\
\hline $\mathbf{5}$ & 100 & 0.4 & 3.0 & 157.80 \\
\hline $\mathbf{6}$ & 100 & 0.4 & 4.0 & 149.02 \\
\hline $\mathbf{7}$ & 100 & 0.6 & 2.0 & 155.64 \\
\hline $\mathbf{8}$ & 100 & 0.6 & 3.0 & 143.57 \\
\hline $\mathbf{9}$ & 100 & 0.6 & 4.0 & 135.58 \\
\hline $\mathbf{1 0}$ & 150 & 0.2 & 2.0 & 244.74 \\
\hline $\mathbf{1 1}$ & 150 & 0.2 & 3.0 & 225.76 \\
\hline $\mathbf{1 2}$ & 150 & 0.2 & 4.0 & 213.20 \\
\hline $\mathbf{1 3}$ & 150 & 0.4 & 2.0 & 208.24 \\
\hline $\mathbf{1 4}$ & 150 & 0.4 & 3.0 & 192.09 \\
\hline $\mathbf{1 5}$ & 150 & 0.4 & 4.0 & 181.40 \\
\hline
\end{tabular}


Asia Pacific Journals

ISBN: 978-81-930411-8-5

\begin{tabular}{|l|l|l|l|l|}
\hline $\mathbf{1 6}$ & 150 & 0.6 & 2.0 & 189.46 \\
\hline $\mathbf{1 7}$ & 150 & 0.6 & 3.0 & 174.78 \\
\hline $\mathbf{1 8}$ & 150 & 0.6 & 4.0 & 165.05 \\
\hline $\mathbf{1 9}$ & 200 & 0.2 & 2.0 & 281.38 \\
\hline $\mathbf{2 0}$ & 200 & 0.2 & 3.0 & 259.57 \\
\hline $\mathbf{2 1}$ & 200 & 0.2 & 4.0 & 245.12 \\
\hline $\mathbf{2 2}$ & 200 & 0.4 & 2.0 & 239.42 \\
\hline $\mathbf{2 3}$ & 200 & 0.4 & 3.0 & 220.86 \\
\hline $\mathbf{2 4}$ & 200 & 0.4 & 4.0 & 208.57 \\
\hline $\mathbf{2 5}$ & 200 & 0.6 & 2.0 & 217.83 \\
\hline $\mathbf{2 6}$ & 200 & 0.6 & 3.0 & 200.95 \\
\hline $\mathbf{2 7}$ & 200 & 0.6 & 4.0 & 189.76 \\
\hline
\end{tabular}

Table 4 Regression analysis for $\mathrm{HAZ}_{\mathrm{PC}}$ versus power, cutting speed, pressure

\begin{tabular}{|l|l|l|l|l|}
\hline Term & Coefficient & SE Coef & T & $P$ \\
\hline Constant & 292.098 & 0.5053 & 578.020 & 0.000 \\
\hline Power & 32.423 & 0.3095 & 104.774 & 0.000 \\
\hline Cutting speed & -25.491 & 0.3095 & -82.373 & 0.000 \\
\hline Pressure & -13.604 & 0.3095 & -43.962 & 0.000 \\
\hline Power * Power & -52.902 & 0.4555 & -116.139 & 0.000 \\
\hline Cutting speed * Cutting speed & -41.805 & 0.4555 & -91.776 & 0.000 \\
\hline Pressure * Pressure & -47.176 & 0.4555 & -103.566 & 0.000 \\
\hline Power * Cutting speed & -4.184 & 0.4376 & -9.561 & 0.000 \\
\hline Power * Pressure & -2.202 & 0.4376 & -5.031 & 0.000 \\
\hline Cutting speed * Pressure & 1.781 & 0.4376 & 4.068 & 0.000 \\
\hline$S=0.875279$ & $P R E S S=61.2891$ & $R-S q=99.99 \%$ & $R-S q($ pred $)=99.83 \%$ & $R-S q($ adj $)=99.97 \%$ \\
\hline
\end{tabular}

Table 5 ANOVA for $\mathrm{HAZ}_{\mathrm{PC}}$

\begin{tabular}{|l|c|c|c|c|c|c|}
\hline \multicolumn{1}{|c|}{ Source } & DF & Seq SS & Adj SS & Adj $\boldsymbol{M S}$ & $\boldsymbol{F}$ & $\boldsymbol{P}$ \\
\hline Regression & 9 & 36910.3 & 36910.3 & 4101.1 & 5353.17 & 0.000 \\
\hline Linear & 3 & 15089.0 & 15089.0 & 5029.7 & 6565.18 & 0.000 \\
\hline Power & 1 & 8410.0 & 8410.0 & 8410.0 & 10977.49 & 0.000 \\
\hline Cutting speed & 1 & 5198.4 & 5198.4 & 5198.4 & 6785.39 & 0.000 \\
\hline Pressure & 1 & 1480.6 & 1480.6 & 1480.6 & 1932.65 & 0.000 \\
\hline Square & 3 & 21719.1 & 21719.1 & 21719.1 & 9449.92 & 0.000 \\
\hline Power* Power & 1 & 8088.6 & 8088.6 & 8088.6 & 13488.16 & 0.000 \\
\hline Cutting speed*Cutting speed & 1 & 5413.3 & 5413.3 & 5413.3 & 8422.89 & 0.000 \\
\hline Pressure*Pressure & 1 & 8217.3 & 8217.3 & 8217.3 & 10725.99 & 0.000 \\
\hline Interaction & 3 & 102.1 & 102.1 & 34.0 & 44.42 & 0.000 \\
\hline Power*Cutting speed & 1 & 70.0 & 70.0 & 70.0 & 91.41 & 0.000 \\
\hline Power* Pressure & 1 & 19.4 & 19.4 & 19.4 & 25.31 & 0.004 \\
\hline Cutting speed*Pressure & 1 & 12.7 & 12.7 & 12.7 & 16.55 & 0.010 \\
\hline Residual Error & 5 & 3.8 & 3.8 & 0.8 & & \\
\hline Lack-of- Fit & 3 & 3.8 & 3.8 & 1.3 & & \\
\hline Pure Error & 2 & 0.0 & 0.0 & 0.00 & & \\
\hline Total & 14 & 36914.1 & & & \\
\hline
\end{tabular}


ELK

\section{Asia Pacific Journals}

As per the estimated regression coefficient, the model equation for $\mathrm{HAZ}_{\mathrm{PC}}$ is

$H A Z_{P C}=292.098+32.423 P-25.491 v-13.604 p-$

$52.902 P^{2}+41.805 v^{2}-47.176 p^{2}-4.184 P v-2.202 P p$

$+1.781 v p$

\section{ELK Asia Pacific Journals - Special Issue}

ISBN: 978-81-930411-8-5

According to the result, laser power's F-value of 10977.49 implies the power is the most affecting parameter in deciding $\mathrm{HAZ}_{\mathrm{PC}}$. Contour plots of $\mathrm{HAZ}_{\mathrm{PC}}$ are shown in figure 1, which indicate the 3-D relationship in two dimensions, with two factors, plotted on the $\mathrm{x}$ and $\mathrm{y}$ scales and response HAZ value represented by contours.

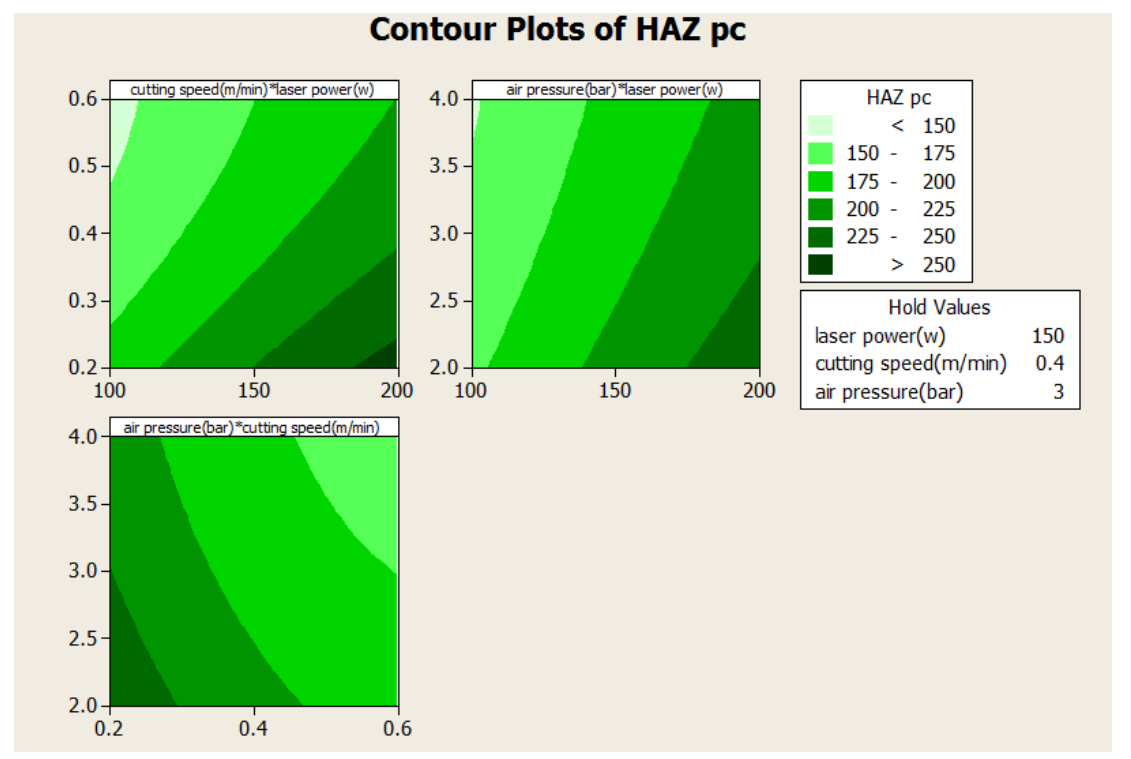

Figure 1. Contour Plots of $\mathrm{HAZ}_{\mathbf{P C}}$

\section{CONCLUSIONS}

In this study, Response Surface Methodology is used to investigate the relationship between laser machining parameter with responses HAZ for Polycarbonate (PC) material. The cutting parameter studied here are laser power, cutting speed and gas pressure.

According to the results, laser power's F-value of 10977.49 implies the power is the most affecting parameter in deciding $\mathrm{HAZ}_{\mathrm{PC}}$. Value of "Prob.>F" less than 0.0500 indicate model terms are significant. In this case laser power, cutting speed, gas pressure and second order terms of laser power, cutting speed, gas pressure as well as the interaction effect of laser power and cutting speed, laser power and gas pressure, gas pressure and cutting speed are the significant model terms. HAZ for PC lies between $0.135 \mathrm{~mm}$ and $0.281 \mathrm{~mm}$ and the dimensions of HAZ is directly proportional to the laser power and inversely proportional to cutting speed and compressed air pressure can observed with the help of model equation. Results can be used to predict the HAZ within the limit of experiments. 


\section{Asia Pacific Journals}

\section{REFERENCES}

[1] Chryssolouris, G. (1991), Laser Machining - Theory and Practice (Mechanical Engineering Series), Springer, New York.

[2] Wilson, J. and Hawkes, J. F. B. (1987), Laser principles and applications, Prentice Hall International, Hertfordshire, UK

[3] Dubey A. and Yadava V. (2008), "Laser beam machining - A review", International Journal of Machine Tools \& Manufacture, 48, 609-628
ISBN: 978-81-930411-8-5

[4] Jain, V. K. (2005), Advanced Manufacturing Process, Allied Publishers Private Limited, New Delhi.

[5] Meijer, J. (2004), "Laser beam machining (LBM), state of the art and new opportunities", Journal of Materials Processing Technology, 149, $2-17$.

[6] Choudhury, I.A. and Shirley, S. (2010), "Laser Cutting of Polymeric Materials: An Experimental Investigation", Optics and Laser Technology, 42, 503-508. Montgomery, D.C., Design and Analysis of Experiments, 2001, John Willey, New York. 